\title{
SESMARIAS - UMA DÁDIVA DO REI
}

\author{
Ubirajara Carlos Mendes
}

\section{RESUMO}

Ocupa-se o tema, de verificação da base fundiária brasileira através do exame da legislação anterior, traçando-se um paralelo entre a pretensa reforma agrária atual e as "terras de Sesmarias". Os estudos demonstram que a "Lei de Sesmarias", originada em Portugal com o intuito de suprir a escassez dos alimentos; face ao abandono do cultivo, daí, a redistribuição de terras para aqueles que pretendiam agricultar, foi aplicada no Brasil sem qualquer adequação, e, além de não considerar as peculiaridades próprias da terra descoberta, também o objetivo da lei foi deturpado; passando a ser utilizada como garantidora das terras conquistadas. As concessões de Sesmarias se fizeram sem critérios, geralmente cedidos por favoritismo politico do Monarca aos amigos do regime, de forma que nem sempre o sesmeiros era o efetivo ocupante, e ainda, se acresceram os problemas pe las diferentes significações das medidas de léguas da época, resultando na incerteza das ocupações, gerando inúmeros latifundios improdutivos e disputas sobre a dominação da terra. A reforma agrária brasileira ainda não aconteceu, pois é dependente de uma política agrária, que venha a resolver os latifúndios improdutivos em algumas regióes, noutras desenvolva colonizações satisfatórias, mas que principalmente, considere as particularidades geográficas e humanas de cada região, com o objetivo da função social da propriedade.

PALAVRAS-CHAVE: Sesmarias; Politica agrária; Reforma agrária; Latifúndios; Função social da propriedade; Regime sesmarial; Peculiaridades regionais.

\section{1- INTRODUÇÃO}

1.1. Dentre as muitas necessidades porque passa o Brasil, certamente, a de maior relevo é a atual preocupação por uma política agrária, entendendo-se como tal, "um conjunto de medidas aptas a influir positivamente na estrutura e na atividade agrária, notadamente em relação àquelas a ela ligados, com o objetivo de alcançar o desenvolvimento econômico e o bem estar da comunidade". (17:73-85).

1.2. O que se evidencia no Brasil atualmente, é uma indefinição fundiária, causada por uma difusão de objetivos e interesses variados, os quais resultam na inadequação da atual Política Agrária, que é inflexivel. Explica-se: em nossa opinião, "sub censura", o que deve informar o que é prioritário deve advir das particularidades de cada região, deste nosso imenso tertitório, admitindo-se as particularidades de cada localidade, computando-se o senso da relatividade que é inerente à pessoa humana, e não se pode esquecer que é para esta que está voltada a Política Agrária.

1.3. As divergências conceptuais de cada região, são realidades que não podem ser desprezadas, dai ser inaceitável a uniformização como padrão nacional, de uma só Politica Agrária. Ora, a Amazônia legał*precisa de colonização, que é um processo menos traumático, e não de Reforma Agrária.

1.4. As diferenças que aqui se apontam, não são só relacionadas com o aspecto geográfico diversificado que existe em nosso País, ou com as diferenças da flora, fauna e hidrografia de cada região, mas também e principalmente, porque os homens de cada região se sensibilizam diferentemente. Se as diferenças fossem apenas da natureza, o homem vencê. las-ia, mas em se tratando de pessoas humanas, deve haver respeito à vontade e atendimento às necessidades particulares, de forma que não săo os homens que devem se adequar à Política Agrária, mas o contrário. As particularidades de que se refere, são realidades palpáveis, podendo-se exemplificar, em termos de Paraná, que o lavrador, o rurícola da regiâo litorânea, diante de uma iđêntica adversidade, se comporta diferentemente do "caboclo" do interior. Este é mais reagente, procurando desde logo as autoridades, a Justiça, concentrando-se em movimentos, sentindo-se "ferido" e por vezes, procura soluções pelas vias de fato.

1.5. O que se defende é uma política regionalista sensibilizada pelas necessidades de cada região, administrada de forma estadual pelos órgãos de terras dos Estados. O que não se admite é uma política agrária como a média das necessidades do País como um todo. Há que se diferenciar o que é diferente.

1.6. A verdade é que, em toda a história agrária, de nosso Pais, não se aprecia um acerto, nem mesmo político ou legislativo, a começar pela legislação das sesmarias que geraram grandes latifúndios improdutivos como eram elas mesmo, justamente por inexistir uma política agrária atenciosa a particularidades. Aliás, em se tratando de Sesmarias a politica nem mesmo era brasileira, mas portuguesa e esta nem mesmo foi adaptada para o caso particular do Brasil, aplicando-se-á aqui como se fosse lá. 
1.7. E nessa diretiva que se procurará desenvolver o pre. sente estudo, tendo em foco a fase agrária das Sesmarias - uma dádiva do rei - e os reflexos desta na formação da política agrária brasileira, que convém se diga, se não é a melhor pelo menos existe, e as criticas visam o seu aperfeiçoamento.

\section{2 -SESMARIAS EM PORTUGAL}

2.1. Muito antes do descobrimento de Brasil, já se discutia em Portugal, uma forma de distribuição de terras para efetiva ocupação agrícola, premida pela situação de abandono do cultivo por partes dos agricultores, que, passo a paso, abandonavam as atividades agrícolas, fazendo do imovel apenas uma extensão de poder, sem o aproveitamento da terra que se perdia em extensas áreas incultas. (20:153).

2.2. Diante da crescente escassez de alimentos e pelo posicionamento negligente dos proprietários, D. Fernando I, rei de Portugal, face ao abandono das atividades agrícolas no País, promulgou em 26.6.1375, uma lei considerada "drástica e violenta" (20:153), que constrangia os proprietários a lavrarem suas terras, sob pena de cessão delas aos que se quisessem lavrar.

2.3. Desta forma surgiram as sesmarias, cujo enigma lingüístico da palavra "sesmaria" já suscitou discussões, preferindo-se juntamente com Costa Porto (16:41), citando Cirne Lima, à concisão, o paresentando nas Ordenações Filipinas: "sesmarias são propriamente as dadas de terras, a ca. sais ou pardieiros que foram ou são de algum senhorio, e que, em outro tempo foram lavradas e aproveitadas, e agora กล̃o o são".

2.4. A concessão das sesmarias se fazia pelo soberano, e era para qualquer interessado, desde que as tomasse para lavrá-las e desde que preenchesse alguns requisitos: “... da. vam e repartyram as terras DE SESMARIA a quaesquer pessoas de qualquer calidade e condicam... contanto que seyam christãos, lyvremente, sem foro nem direito algum, somente o dízimo que serão obrigados de pagar a hordem do Mestrado de noso Senhor Jhesu Christo de tudo o que nas ditas terras ouverem". (16:41).

2.5. Bem se vê a influência da Igreja neste ponto, que influia na escolha do sesmeiro, servindo muitas vezes como "árbitro", como na partição do Mundo entre Espanhóis e Portugueses realizada pela Bula Intercoetera, $(21: 26-27)$ datada de 3.5.1493, que fora antedatada por Sua Santidade, Alexandre VI, influindo também no Brasil, pois pela bula da partição, o Brasil era de Portugal antes mesmo de ser des. coberto. 10

2.6. As sesmarias têm a particularidade, portanto, de serem soluções procuradas pelas necessidades do Reino de Portugal, cuja observação do rei resultou no seguinte: "disfallicimento de mantimentos de trigo e cevada que amtre todalhas terras e provincias do mundo soyam seer muy abastadas", de sorte que "estas cousas sam postas em tamanha carestia que aqueles que ham de manter fazendas em qualquer grau nom podem aver estas cousas", (16:42) dai que: "todos os que tiverem herdades próprios, aforados, emprazados, ou por qualquer outro título que sobre as mesmas lhes dê direitos, sejam constrangidos a lavrá-las e semeálas..." (13:11-12).

2.7. Após o reinado de D. Fernando, a "lei das sesmarias" sofreu algumas revisões por D. João I, tendo sido coletada nas Ordenações Afonsinas de 1446, como também nas
Ordenações Mạuelinas de 1503, significando que o Brasil, descoberto em 1500 , recebia como sesmarias, sua primeira fase estrutural fundiária.

\section{3 - PERIODO DAS SESMARIAS NO BRASIL}

3.1. É imperiosa a referência, aos objetivos essencialmente extrativistas desempenhados pela politica portuguesa para a Terra de Santa Cruz, quando do seu apossamento. A política imediatista de Portugal visava o ressarcimento dos investimentos com as primeiras expedições e de forma assistemática e ametódica principiou a ocupação do solo brasileiro, sem saber exatamente o que fazer com a grande descoberta.

3.2. Na verdade, o Brasil passou a ser "uma fazenda do rei" ( $3: 12)$, tendo a posse como fato da conquista da terra, sem qualquer plano racional para sua utilização.

3.3. Como já se disse, a Bula Papal Intercoetera estabeleceu que todas as terras descobertas a 100 léguas a Oeste de Cabo Verde seriam de Portugal, mas, os portugueses, suspeitando que existiam mais terras por descobrir, em 1494 fizeram novo pacto com CASTELA, passando de 100 para 370 léguas, firmando-se o pacto conhecido como Tratado de Tordesilhas, o qual foi ratificado por bula do Papa Júlio II.

3.4. Com o descobrimento do Brasil, a Espanha percebeu o grande logro em que incidira, planejando através do seus jurisconsultos, polêmicas sérias em torno desse pacto internacional, com o sentido de anulá-lo ou de transformá-lo para a conquista de ocupação, daí, por razões precipuamente de segurança, e assim mesmo só em 1530 , é que Portugal mandou a expedição de Martin Afonso de Souza, tida como colonizadora.

3.5. Com Martin Afonso de Souza vieram 400 homens (20:154), que na sua maioria eram degredados, criminosos que haviam infringido penas capitais, e a eles "El-Rei, ordenava ao feitor e oficiais da Casa da India, que dessem "machados e enchadas e todas as mais ferramentas às pessoas que fossem povoar o Brasil" (20:154), dessumindo-se que, verdadeiramente o governo português desejava primeiramente o domínio da terra pela posse efetiva, acreditando mais na capacidade bélica dos homens que degregava, do que na sua produtividade agricola.

3.6. O regime vigente era o de Sesmarias, mas se implantava dissociado do intuito primeiro de cultivo, de agricultura.

3.7. Na verdade, tal sistema nem deveria ser utilizado para o caso do Brasil, pois já observou que era especifico para uma determinada situação em uma determinada época para Portugal. A começar porque o regime de sesmarias só se aplicava para propriedades abandonadas, e no caso do Brasil, as terras eram virgens, podendo ser integralmente aproveitadas, não existindo propriedades abandonadas, nem tampouco tinha o intuito de prover alimentação.

3.8. Foi por conselho de Diogo de Gouveia, diplomata português que se ocupava em estudos de colonização, que o rei João III resolveu adotar no Brasil, o sistema de colonização das capitanias hereditárias, face ao sucesso de tal sistema nos Açores, que culminou por não servir ao Brasil.

\section{4 - CAPITANIAS HEREDITÁRIAS}

4.1. Foram criadas 14 capitanias hereditárias, de 30,50 e 
100 léguas da costa até a linha de Tordesilhas, mas na verdade extrapolaram o marco final, pois ao certo, só era conhecido o início. As capitanias hereditárias eram na realidade, grandes latifúndios, e latifundiária nasceu a nossa política territorial.

4.2. Nesse sentido, afirma o professor Walđemar Ferreira (6:83):

"Com a extensão territorial imensa, que apenas se sabia que começava na costa maritima e cujos fins se perdiam no mistério $e$ na lenda, à dádiva de terras de sesmarias tinha que iniciar, e assim aconteceu, a politica territorial latifundiária. Cada sesmaria era um latifúndio".

4.3. Expendendo idêntico ponto de vista o professor Costa Porto afirma ter sido no Brasil, a causa principal do latifúndio. (16:58-59).

4.4. Nesse sentido também se expressa Altir de Souza Maia: "a sesmaria é o latifúndio, inacessível ao lavrador sem recursos" (13:15).

4.5. Igor Tenório, comentando a Evolução do Regime de Terras, diz:

"As concessões de terras muito maiores do que o permitido em lei feitas às pessoas mais chegadas ao governo deram origem ao espirito de latifúndio, que até hoje perdura no Brasil"'(21:33).

4.6. Como afirma Costa Porto, as sesmarias eram uma espécie de "reforma agrária" (15:43), que para a realização da política redistributiva de terras, determinava que houvesse "dous omees boôs dos milhares que y ouver" - chamados sesmeiros, surgindo como o distribuidor das terras, e que, pouco a pouco, foi mudando de sentido, passando a ser usado como o beneficiário das datas, o colono ou morador.

4.7. Depois de 125 anos de uso deste sistema, já obsoleto em Portugal (15:43) transplantou-se-o para o Brasil, com o absurdo de não se fazer uma alteração sequer, e pior, já se sabendo que não funcionava, implantando-se um confuso sistema latifundiário, sem medidas previamente estabelecidas, apenas com a consciência de áreas enormes.

4.8. Apesar de conter a "Tei" um preceito restritivo quanto ao tamanho das concessões de SESMARIAS $(15: 43)$, os distribuidores do solo não poderiam ceder terras a mais, do que razoavelmente pudesse aproveitá-las: “... avisados nam deem mayores terras a huma pessoa que ao que razoavelmente parecer que as poderam aproveitar", contudo, o preceito era genérico demais com uma carga subjetiva sem parâmetros definidos, nunca observado para o caso do Brasil.

4.9. A carta foral de 1530 determinava a concessão de áreas que "boamente possa cultivar" com glebas de tamanhos "normais" para a cultura ou criação, estabelecendo-se os casos de descanso, floresta para aproveitamento de madeiras, campos naturais e outros. (19:155).

4.10. Apesar desta carta foral, a Metrópole fazia vistas grossas aos incontroláveis desejos de formar latifúndios, visto o interesse pelo domínio efetivo da terra, mesmo que este se desse por meio de extensas fazendas.

4.11. Outro aspecto a ser destacado é que, apesar da criação das 14 Capitanias, ou seja, o desmembramento do Brasil em grandes áreas, o Rei não as doava, mas apenas fazia uma concessão de tais áreas aos sesmeiros, pois pretendia fundar o seu império, numa terra dominada, onde, valo- rizada, receberia seus impostos. Dai Octávio Mello Alvarenga (2:15-16), ter afirmado:

"Ora o Rei de Portugal não dava terras. Ele fazia uma espécie de concessão aos sesmeiros, para sua efetiva utilização econômica. $O$ que queria era fundar um Império. Queria que o sujeito trouxesse dinheiro, homens, ferramentas, animais, lavrasse a terra, valorizasse-a com o que o Rei receberia seus impostos, tanto que reservava certos direitos regaleanos. Basta o fato de não terem cumprido suas obrigações como, geralmente, não cumpriam para com a Corte Portuguesa, para que caissem em comisso, por diferentes maneiras.

Este breve trecho de voto, proferido no STF pelo ministro Aliomar Baleeiro, contém elementos que serão oportunamente estudados. Conviria, entretanto, desde logo, pensar-se numa possivel equivalência de o "imperialismo" lusitano (fundar um império, para receber vantagens, antes mesmo de estruturar-lhe as bases politicas) conter. dois elementos paradoxais: em primeiro lugar, a obrigatoriedade da exploração economicamente válida, prenunciando o que seria enfatizado como "função social"; em segundo, essa mesma exploração vincular-se à vantagem maior (globalistica) de uma administração central, representada pelo Império. Era o prenúncio do capitalismo estatal, o embrião de tendência desenvolvida bem mais tarde, em outra etapa histórica. No seu explêndido Estudo sobre o Sistema Sesmarial, Costa Porto observà a propósito de Portugal (de D. Fernando) e do Brasil (de D. João III) a existência de apenas um ponto comum entre ambos: solo sem cultura.

$A$ "Lei de Sesmaria" foi baixada em Portugal para enfrentar a indolência dos senhorios, que nem trabalhavam nem permitiam que outros o fizessem; no Brasil, havia, pelo contrário, carência de braços - de braços que se subordinassem ao dominio portuugês.

No Reino, escreve Costa Porto, distribuia-se o solo a fim. de possibilitar a produção e, com ela, assegurar o abas-. tecimento; no Brasil, visava-se decerto, à produção, mas; tendo em vista de maneira precipua, o povoamento, mesmo porque a população autóctone, aqui encontrada, começava a ser dizimada".

4.12. Em voto proferido no julgamento do recurso extraordinário n? 51.290-60, o saudoso Ministro Aliomar Baleeiro afirmou:

\footnotetext{
"As terras do Brasil foram objeto de conquista e posse, por Pedro Alvares Cabral, para o Rei de Portugal. Ela passou a ser uma fazenda do Rei, ficando no dominio real até a intependência, quando foi transferida para o Patrimônio Nacional, lá permanecendo todo o tempo do Império, até que o artigo 64 da Constituição de 1891 a distribui aos Estados em cujos limites se encontrava. Então, os Estados, como sucessores da nação brasileira, $e$ a nação brasileira como sucessora do Patrimônio pessoal do Rei de Portugal, não necessitam trazer nenhum titulo. O título é a posse histórica, o fato daquela conquista de terra. A terra, no Brasil, originariamente era pública. $O$ Rei desmembrou pedações, áreas enormes, as chamadas sesmarias, e doou-as. Houve esse processo até quase a Independência. Depois da Independência estabeleceu-se que não poderiam ser mais objeto de doações ou concessões".
} 
4.13. Todas as terras portanto, à época das sesmarias eram do governo portugues que as cedia para cumprimento de objetivos do Rei. Diz Paulo Tormim Borges: (4:67) que: "Não é demasiado longa a história de nossa propriedade territorial. Mas esta eriçada de vaivéns, e, muitas vezes, de incompreensão do Poder Público sobre a importância de levar os imóveis rurais à propriedade particular".

4.14. Desenvolvia-se neste período um regime semi feudal em que o Estado e a propriedade se estruturavam dentro dessa filosofia, com enormes extensões de terra sob o mando e poder dos senhores que detinham o poder absoluto sobre as pessoas e as coisas, com os bens empatados em engenhos de açúcar e escravos, sujeitando agricultores, agregados e assalariados mais categorizados.

4.15. Já para o professor Raymundo Laranjeira, não se trata de um sistema feudalista o que os lusitanos trouxeram para o Brasil, diz:

"A cobiça de Portugal em servir-se do nosso território, para usufruir melhores dádivas econômicas que a simples atividade extrativa do pau-brasil não estimulava, e o desejo de salvaguardar as novas terras das investidas estrangeiras, fizeram com que se desse azo, aqui, à tentativa de uma exploração mais enérgica do solo, em se tratando um maior número de pessoas, a quem também incumbiria a defesa territorial. $E$ ao decidir a Coroa sua tarefa de colonizar, cuidou ainda, naturalmente, de que a fruição dos terrenos brasileiros pudesse não se proceder da maneira descontrolada e timida dos primeiros tempos; antes procurou dimensionar a respeito da ocupacāo e uso da terra, através de competentes institutos legais, fazendo transpor para cá o mesmo propósito do regime terreal vigente no pequeno reino peninsular.

Em que pesem os vicios e fracassos da empresa lusitana, o certo é que a esquematização fundiária, traçada para o Brasil, teve o mérito de refugir do modelo feudalista, para obedecer ao programa do sesmarilismo, socialmente menos conturbador, e que estava em vigor pleno no Portugal do século XVI"(11:1-2).

4.16. Sobre este assunto, o professor Nestor Duarte afirma: "A organização portuguesa de ocupação de terras brasileira era feudal. Um feudalismo de sentido político e de sentido econômico, sem a menor dúvida. (5:12-13).

4.17. Roberto Simonsen, defende a tese segundo a qual "não é o feudalismo que caracteriza o sistema dos donatários, mas sim a inversão capitalista que ele traduz". (18: 124-127).

4.18. As capitanias hereditárias terminaram por mostrar um fracasso, contudo, por fidelidade à história e porque efetivamente foi assim o começo agrário no Brasil, cumprese observar uma primeira fase de fracasso. Diz Costa Porto:

"O regime das Capitanias, foi entretanto, efêmero e pela própria fragilidade intima e pelo pequeno tempo em que funcionou, quase não deixou traços em nossa estrutura interna, não passando de mero incidente episódico, sem repercussôes decisiva em nossa evolução" (15:25).

\section{5 - OS PROBLEMAS DAS SESMARIAS}

5.1. O desenvolvimento jurídico do direito agrário como sistema jurídico autônomo de estudo "tem uma breve história quase completamente incluída no nosso século, e, todavia, tem já um desenvolvimento doutrinário relevante nas
Universidades e uma elaboração complexa nas legislações de todos os países do mundo". (12:3).

5.2. Contudo, a função social da propriedade já se faz sentir até mesmo quando das Sesmarias, muito embora só atualmente se depreende com mais acerto o verdadeiro significado de função social da propriedade, que entre nós foi objeto da ímpar percuciência de Orlando Gomes, que comenta:

"O que se procura significar, ao relatar o fenômeno evolutivo da propriedade em sua projeção na realidade social dos dias correntes, na fórmula que atribui a seu exercicio uma função social é, em sintese, que sob esse aspecto, vem acompanhada de certos ônus e deveres para com a coletividade, impostos pelo Estado. deveres $e$ ônus que reduplicam e são estabelecidos numa escala que vai desde as proibiçóes restritivas do exercicio do direito até a condenação da propriedade inerte, traduzida na obrigação do proprietário de utilizar seu bem na forma de interesse coletivo. Sua atividade, deixa de ser livre em face da operatividade externa da função sobre a estrutu-. $r a$, primando o elemento teleológico sobre o estrutural. Conclui-se, em definitivo, que a atividade do proprietário de bens de produção não pode cumprir-se em contraste com a utilidade social, somente se justificando sua proteçăo juridica se em conformidade com esse propósito".'(9:12).

5.3. Daí que a função social da propriedade, mostrava-se latente no regime sesmarial, porque o proprietário da gleba não podia ou não queria lavrá-la, dever-se-ia transferir a quem a explorasse, modificando-a em função da necessidade coletiva, com o seu trabalho: "Se por negligência ou contumácia os proprietários não observarem o que fica determinado, não tratando de aproveitar por si ou outrem as suas herdades, as Justiças territoriais, ou as pessoas que sobre isso tiverem intendência, as dêm a quem as lavre, semeie por certo tempo, a pensão ou cota determinada". (13:12).

5.4. E certo que a função social implica em restrições à faculdade de gozo e disposição, como ensina o mestre Paulo Guilherme de Almeida:

"Obviamente, a sustentação de uma função social a ser cumprida implica restriçôes à faculdade de gozo e disposição do proprietário em relação ao seu bem. E dá validade de tais restrições, pois decorrem estas da necessidade de tutelar a pacífica coexistência na vida em sociedade, para o que o interesse público deve prevalecer sobre o interesse particular." (1:19).

5.5. O que visava o regime das sesmarias era necessidade específica de Portugal, que diretamente pretendia suprir a alimentação faltante, e, indiretamente o aproveitamento racional do solo, a elevação econômica e social do lavfador, o desenvolvimento do próprio País, que, deveria se realizar em propriedades conforme a área possivel de sua utilização pelo beneficiário. No Brasil, - repetimos -, a legislação sesmariense não foi sequer adaptada e nem era o caso de aplicação no Brasil, por ser voltada especificamente para terras já anteriormente ocupadas.

5.6. Esta aplicação inadequada causou um retardamento até o ano de 1850 , para uma verdadeira tomada de posição no sentido de se enfrentar o problema ocupacional no Brasil que era confuso e indecifrável, que, pela falta de um plano próprio-de colonização e exploração agrária, diminuiu a 
intensidade do sentido da função social, principalmente pela gama absurda de poderes concentrados no donatário, depois o "Senhor de Engenho", que não facilitaram o desenvolvimento dos pequenos lavradores, como se verá adiante. O próprio latifúndio é um entrave à distribuição da terra de forma racional, conseqüentemente impede o desempenho ideal da função social da propriedade rural.

5.7. O regime das Sesmarias, idealizado para Portugal, onde havia muita gente e pouca terra (território de $88 \mathrm{mil}$ $\mathrm{km} 2$ - cabe dentro do Estado de Pernambuco) encontrava no Brasil o contrário - pouca gente e muita terra, cuja afirmativa a própria história do Brasil confirma: com o desenvolvimento dos engenhos, a primeira necessidade foi a falta de mão-de-obra, que passou a ser suprida pelo braço escravo, servindo-se de índios e negros, sendo os primeiros abolidos da escravidão pela Carta de Lei, de 1 de abril de 1680 , quando então passou-se a importar da África, o negro escravo; importou-se da Europa o técnico e a maquinaria. (7:3).

5.8. Para o pequeno lavrador, branco, católico e português, o regime das sesmarias foi ainda pior, e até hoje se ressente dos reflexos emanados pelas sesmarias, não tem nem mesmo oportunidade para crescer, aliás mal podia sobreviver. Explica-se: o "senhor de engenho" apossou-se de tantas sesmarias quanto pode, separando as terras boas e férteis para si, fornecendo dentro delas, as piores para o lavrador que obrigava-se a plantar. Este plantava e era obrigado a entregar toda a sua produção ao Senhor de Engenho, o qual transformava a cana e entregava a metade do produzido, em açúcar, descontando ainda, o aluguel da terra.

5.9. O lavrador não possuia recursos para construir o seu próprio engenho, nem tampouco adquirir escravos, porque custavam caro. Se não entregasse a produção de cana ao senhor de engenho, ou este não a aceitasse, ainda assim metade the era devido, além do que, nos relata o professor Sodero, que economicamente o açúcar pouco valia, visto que, somente a Capitania de Pernambuco, em 1576, exportava cerca de 70000 (setenta mil) arrobas do produto e, sete anos após, mais de três vezes esse montante. (20:159) Ainda da pesquisa do professor Sodero, cita-se:

"Nem é preciso que se diga que houve numerosos abusos e falta de escrípulos no tratamento dado por um ao outro. E, por incrivel que pareça, somente em 1941, com a promulgação do Estatuto da Lavoura Canavieira (Decreto-lei no 3.855, de 21 de novembro), foi que uma disposição legal veio pôr, cobro a esa situação, regulando juridicamente as relações entre os fornecedores de cana fos então chamados "levradores") e as usinas (que substitui" ram os senhores de engenho bang; $\hat{e}$.).

Com uma produção comercial totalmente feita para a exportação - de ve que o interesse pela transação estava na Europa e, obviamente, não havia mercado interno para o consumo - utilizando as melhores terras do Nordeste brasileiro e na extensão que quisesse, com mercado garantido para o produto, o senhor de engenho buscou mais e mais. Näo admitiu culturas de subsistência: o que rendia era o açucar (cana), o escravo era caro demais para produzir mandioca, feijão e milho, abóbora ou boi. $E$ começou a monopolizar a terra, introduzindo o sistema de exploração rural batizado, mais tarde, pelo nome de plantation". (20:159).

5.10. Augusto Zenum, em "Direito Agrário e sua dinâmica", comunga a opinião de que desde o século $\mathrm{XV}$, já surgia a importância da função social da propriedade, afirma: "Claro é que não vamos discutir quanto ao fato de alguns ou de muitos sesmeiros não terem cumpridos aqueles preceitos, ou se perderam as terras, ou se com elas continuavam, pois o importante é saber que, desde o século XV, já existia uma norma condizente com o direito agrário e, em especial, com o desempenho da função social da propriedade". (22:14).

5.11. Cumpre-se anotar, nesse mesmo sentido a lição de Altir de Souza Maia: "... Em que pese tal paradoxo, os dispositivos do remoto diploma legal evidenciam, desde então, a preocupação do Legislador Imperial de impor à terra o cumprimento de sua função social e desenvolvimentista." (13:14).

5.12. Outra ocorrência anotada no período sesmarial que se reflete até nossos dias, é o chamado latifúndio monocultor, principalmente no Nordeste, onde só se plantava a cana-de-açúcar. A diversificação das culturas só era tentada pelo lavrador, através de pequenas "roças" para consumo familiar, onde se plantava a mandioca, o arroz, o feijão. Certamente, se o pequeno lavrador não tinha possibilidade de concorrer com o donatário ou "senhor de engenho" era de se esperar se arraigasse o fortalecimento da monocultura, monopolizadora da terra.

5.13. O lavrador só podia produzir por processos arcaicos aprendidos pelos indígenas, de forma empírica, sem cientificismo algum, via de conseqüência, o resultado da cultura era insuficiente. O professor Fernando Pereira Sodero, em examinado o tema fez a citação do pensamento de Oliveira Vianna: "... o latifúndio do período colonial resume e absorve em si toda a vida em derredor: nẫo deixa espaço para o pequeno e médio proprietários rurais, vivendo independentes em seu pequeno domínio, à ilharga do grande domínio, e tão autônomos quanto ele. Pelo menos, a tendência do grande domínio é entravá-los, asfixiá-los, eliminá-los, criando um ambiente impróprio à sua vitalidade. Nos seus regimentos e alvarás, a Metrópole procura, é verdade, defender e valorizar os pequenos domínios, obrigando os grandes senhores de engenho a moerem a cana dos lavradores vizinhos. Nem sempre, porém, os senhores de engenho cumprem essa obrigação". (20:159).

5.14. Sob o ângulo de visada da colonização, aparecem ainda piores as conseqüências das sesmarias, por ocorrer um total distanciamento dos preceitos que daquele regime emanaram. Paulo Garcia 8 criticou duramente o regime sesmarial, considerando "inútil e antiquado regime que somente causou danosos resultados e acarretou conseqü̈entes perniciosas à política de colonização".

5.115. Quanto às concessões das sesmarias, estas se fizeram sem qualquer controle, geralmente cedidas por favoritismo político do Monarca aos amigos do regime, sem se fundar nas premissas do sistema em execução. Tal afirmação vem dos estudos sobre dominialidade, promovida por uma Comissão do Distrito Federal: "O regime das sesmarias, geralmente concedidas por mero favoritismo dos Agentes da Coroa Portuguesa e, depois, também por agentes de Governos Imperiais do Brasil, gerou a classe privilegiada dos "detentores" das vastas terras que nem sempre eram razoavelmente aproveitadas e muitas vezes nem ao menos ocupadas".

5.16. Em outro ponto, as sesmarias exercitavam as extensões das glebas em léguas, que, segundo Fernando Pereira Sodero $(20: 60)$, existiam, pelo menos uma série de seis espécies de légua, cada qual com uma medida diferen- 
te. Carlos Ferdinando Mignone, diante das diferentes significações das léguas existentes, afirma: "conclui-se, assim, não ter existido na legislação portuguesa uma área padrão que servisse de base para a concessão de terras no Brasil, isto até a lei de terras elaborada depois da Independência, em 1850." (14:20).

5.17. Ora, se não existia uma medida padrão, ou uma medida referencial, não era possível que qualquer documento, como as próprias cartas forais, trouxessem a certeza da afirmação de ser determinada área, aquela que o sesmeiro apresentava e ocupava.

5.18. Também a noção vaga do que era considerado "aproveitamento", fazia com que não se falasse em abandono da sesmaria pelo incomisso de não aproveitamento. É imperioso, neste ponto, se fazer a citação de Costa Porto:

"Além disso - e fator de maior peso - o conceito de "aproveitamento" findava vago e impreciso, coisa quase simbólica - espécie de "possessio longa manu" dos romanos, simples manifestação exterior do "animus dominii": o fato material de "cavar o chão", plantar árvores frutíferas, ensaiar medıocres plantações de lavoura, soltar apenas algumas cabeças de gado, fazer cercas e aguadas, construir casas rústicas e quase mais nada, de sorte que somente de raro em raro se poderia falar em abandono da sesmarias pelo incomisso de não aproveitamento". (15:44).

\section{6 - FUGA DOS OBJETIVOS DAS SESMARIAS}

6.1. O desvirtuamento do regime sesmarial se deu desde a implantação do mesmo, em 1530 , visando o governo lusitano consolidar a sua dominialidade, afastando outros pretendentes ao solo brasileiro, pela efetiva ocupação.

6.2. Pelo governo português houve a divisão da terra descoberta em latifúndios enormes, fugindo-se a uma divisão razoável, concentrando poderes excessivos aos donatários que asfixiavam a iniciativa de pequenos e médios lavradores, submetendo-os a um aluguel elevado da terra, obrigando-os a entrega das suas safras, de modo a não permitir a expansão destes.

6.3. Perdeu-se completamente o senso razoável da avaliação de "aproveitamento", que passou a significar qualquer coisa transformada na área, porque Portugal objetivava o aumento de sua dominialidade "sertão à dentro" em nítidos interesses ocupacionais.

6.4. A Coroa Portuguesa passou a dar de sesmarias pela escolha de favoritos, de forma eminentemente politicas, discriminatória, em que o beneficiário ou protegido, vivia na cidade, e dela comandava os requerimentos de sesmarias, gerando um conflito de duas classes: a dos sesmeiros e a dos titulares ocupantes, porque, nem sempre este, que descobriu e permaneceu na área, trabalhando-a, era o aquinhoado com a sesmaria.

6.5. $\hat{\mathbf{E}}$ que, na colonização dos sertões, bandeiravam particulares enfrentando toda sorte de imprevistos, para justamente requerer as terras como pagamento de seus serviços, e descoberta novas terras fazimo valer direitos de sesmarias, que nem sempre era reconhecido ao bandeirante, mas ao "cortesão amigo" da Coroa.

6.6. O professor Sodero apresenta o seguinte:

"Acontece que nem sempre o povoador, que descobriu e ficou na terra, frutificando-a com o suor de seu rosto, era o aquinhoado com a sesmaria e sim o potentado que era cortesão do Governador-Geral na Bahia.
A propósito, recorde-se o quanto lutou Domingos Jorge Velho, que, à sua custa, levou um grupo de paulistas, mamelucos, índios e negros para Pernambuco e Alagoas, para dizimar o quilombo dos Palmares, nos fins do século XVII. Depois de todos os sacrifícios, ao requerer a sesmaria da terra onde se localizara (ele e seus comandados), quase viu seus esforços por terra, tendo sido obrigado a mandar procurador a Lisboa, para fazer valer seus direitos sobre a gleba que escolhera e cultivara - depois de saneada a região à sua única custa.

Nem as Ordenações do Reino, nem a legislação extravagante sobre as sesmarias, aplicavam-se devidamente. "Em primeiro lugar - adverte Costa Porto, o conflito entre a lei e a realidade terminou, como sempre, deturpando a pureza do sistema, tornando-lhes os princípios básicos e fundamentais quase letra morta ou, quando aplicados, levando a conseqüências opostas àquelas do Reino".

E, citando Ennes, in "A Guerra dos Palmares", diz que na pendência em torno de tais terras, reclamando contra as exigências do Alvará Régio de 12.3.1695, Domingos Jorge Velho, pondera que "as clauzulas e condiçoens das leys e ordenaçoens q. ha nesta materia de semelhantes sesmarias, e que estão expressadas em $1.4^{\circ}$ das Ordenações tt 43 , e explicadas em os dezesseis $\S \S$ delles, näo se sabe que em tempo algum fossem observadas nestas conquistas do Brasil" (nota: grifo do original).

No citado livro de Barbosa Lima Sobrinho há capítulo muito elucidativo e de grande importância para o estudo que estamos realizando, denominado "sesmeiros e povoadores". Mostra o historiador pernambucano como se procedeu a luta entre o potentado amigo do Governador e poderoso pela vastidão das terras que possuia, fossem engenhos, fossem cabeças de gado, escravos, etc., vivendo na cidade do Salvador e requerendo sesmarias - e o povoador, longe do bafejo oficial, contando com parcos recursos e nenhuma proteção junto aos poderosos, cultivando a terra e cuidando do gado, mantendo afastado o silvícola - e ainda por cima lutando contra o latifundiário que cobiçava e requeria exatamente a sua gleba.

"Assim é que se formaram as duas dasses dentro da mesma sesmaria: a dos titulares e a dos ocupantes, a dos sesmeiros e a dos posseiros. Como também năo se obedecia a limites precisos, na concessão das cartas, foi crescendo na história colonial, a extensão de terras que de fato dominavam. Titular de sesmaria não era quem estivesse disposto a trabathar um pedaço de terra, mas o homem da cidade, o homem influente, que sabia como requerer as cartas e possuia força bastante para obtenção do deferimento e da confirmação". $(19: 170-71)$.

6.7. Algumas tentativas foram feitas visando melhora nas aparentes deficiências da sistemática das Sesmarias, como a Carta Régia de 27.12.1695, estabelecendo o tamanho das sesmarias em quatro léguas por uma de largura, posteriormente, três por uma. Mas o que significava uma légua? Só em 1809 é que se fixou em 3.000 braças ou 6.600 metros lineares, estabelecendo-se então a extensão da légua.

6.8. Nem mesmo o Decreto de 20.10.1753, que proibia a concessão de Sesmaria sem a prévia medição e demarcação, foi suficiente para evitar a concentração monopolista do poder econômico nas mãos de poucos.

6.9. Somente em 1795, com o Alvará de 5 de outubro, chamado de "Lei das Sesmarias" é que se elaborou para o caso especial do Brasil, tendo sido suspenso em 10.12.1976, 
por outro Alvará.

6.10. O Alvará de 1975 continha 29 artigos tratando em síntese, o seguinte:

1. não poderia ser concedida sesmaria a quem já tivesse sido beneficiado anteriormente ( $(\mathrm{XI})$.

2. proibia-se a sua concessão a estrangeiros;

3. as religiões não podiam suceder nas sesmarias;

4. estabelecia a área máxima a ser concedida, conforme a localização, de três léguas até meia légua em quadra, estas nas imediações dos grandes povoados ( $\S \mathrm{XI}$ e VII);

5 . ao ser concedida, a sesmaria deveria ser medida dentro do prazo de um ano, e as de concessão anterior, demarcadas dentro de dois anos, prevendo-se a permanência de certas obrigações do concessionário de dar caminhos públicos e particulares para fontes, portos, pontes e pedreiras $(\S \mathrm{V})$.

Instituiu a lei dois registros de sesmarias: o primeiro, a cargo das Juntas ou Provedorias da Fazenda e o segundo, a cargo das Câmaras Municipais, reservado para estas o das Sesmarias situadas dentro dos termos. Simplificou os processos de normalização das sesmarias e estabeleceu doação às Câmaras, de uma área de quatro léguas, em torno das cidades e vilas, dentro de um raio de seis (6) léguas, para que administrassem e tirassem rendas de foro.

A exata aplicação de tais disposições legais, significaria, porém, quebrar o império econômico de muitos e, tamanha confusão causou o ato da Metrópole, que posteriormente foi ele suspenso, entrando em vigor novo Alvará que consolidava toda a matéria pertinente às sesmarias, eis que o trato do assunto desviara-se cada vez mais das Ordenações para cair sob o domínio das leis especiais.

Observe-se, a propósito, que já em 1677, D. Pedro II, no Regimento que deu a Roque da Costa Barreto, nomeado Governador-Geral do Brasil, traça "normas especiais para a distribuição de terras de sesmarias, dado que não bastavam. os excassos princípios das Ordenações e o tumultuário disciplinamento marginal subsequiente".

O Decreto de 10.12.1796 - que suspendeu a execução do Alvará mencionado, de 5.10.1975 - tem a seguinte redação, que é a justificativa oficial de um fracasso no sentido de coibir a concentração de terras nas mãos de alguns proprietários: "Tendo-me sido presentes os embaraços e inconvenientes que podem resultar da imediata execução da sabia lei de sesmarias, que fui servido mandar publicar pelo meu conselho de Ultramar; seja porque nas circunstâncias atuais não é o momento mais próprio para dar um seguro estabelecimento às vastas propriedades dos meus vassalos nas províncias do Brasil; seja pela falta que há ai de geômetras, que possam fixar medições seguras e ligadas inalteravelmente a medidas geométricas e astronômicas, que só podem dar-lhes a devida estabilidade; seja finalmente pelos muitos processos e causas que poderiam excitar-se, querendo por em execução tão saudáveis princípios e estabelecimentos, sem primeiro haver preparado tudo que é indispensável para que eles tenham uma inteira e útil realização; hei por bem determinar que o Conselho Ultramariano, suspenda por ora a execução e efeitos dessa saudável lei". (19:170-71).

\section{7 - FIM DO REGIME DAS SESMARIAS}

7.1. Apesar das tentativas de recuperação do então sistema sesmarial, era inevitável a sua decadência, porque não podia corrigir o principal defeito, o latifúndio.

7.2. Nas disputas entre os ocupantes e os donos das con- cessões, se revelou uma desobediência incontrolável, ou como afirma Luiz de Lima Stefanini (13:15-16): "as sesmarias já haviam entrado num período crítico de ilegalidade e inadimplência..." "A propriedade era quase inatingivel para aqueles que realmente eram agricultores e tinham como único patrimônio o braço para trabalhar e cultıvar pequenas áreas. Irreversivel seria a grande intrusão em terras já doadas e em terras ainda não distribuídas, onde o período está assinalado por esta característica predominante: ocupação em massa. Desateve-se à formalidade de pedf́las ao Go vernador, porquanto, após a expedição da carta de "sesmaria", deveria, ainda, pagar o foro, que era arbitrado pela extensão das léguas quadradas, observar as obrigações de cultivá-las, sujeitar-se a toda sorte de dificuldades deste risco de atuação, e, por fim, solicitar a confirmação real.

7.3. Também, a vinda da família real para o Brasil acossadas pelas tropas napoleônicas, em 1808, fomentou o desenvolvimento agropecuário com maior intensidade, que somando-se às ocupações dos colonos humildes sobre as concessões dos latifundiários, estes não mais sob os favores da Metrópole, desenvolveu-se um fortalecimento, sentido, com um ambiente de descaso às sesmarias.

7.4. Altir de Souza Maia, citando o mestre Junqueira, relata ter sido a carta de um humilde agricultor da Comarca de Rio das Mortes-MG, de nome Manoel José dos Reis, que detonou o fim das Sesmarias, pois suplicava ao Imperador que não concedesse Carta de Sesmarias sobre o pequeno trato de terra por ele cultivado, de onde tirava o sustento de sua prole. (13:16).

7.5. O sistema de Sesmarias vigorou até 17 de julho de 1822 , resolução esta que foi confirmada em 22 de outubro do ano seguinte, por D. Pedro, que determinou "se suspendessem todas as sesmarias futuras", até a convocação da Assembléia Geral, Constituinte e Legislativa do Império, mandava "mui positiva e terminantemente", a todas as Juntas dos Governos das Províncias, que, "se abstivessem de conceder sesmarias", até que a Assembléia regulasse a matéria.

\section{8 - CONCLUSÕES}

8.1. O instituto jurídico que regulava a concessão das sesmarias, foi o instrumento jurídico disponível que norteou a destinação das terras no Brasil até o ano de 1822 , marcando o início da política agrária em nosso País, influenciado pelas concepções lusitanas até a nossa Independência.

8.2. O plano sesmarial aqui aplicado só foi particularizado às necessidades locais, em 1795, 420 (quatrocentos e vinte) anos após a criação do regime sesmarial por D. Fernando, e mesmo assim, só valeu por um ano, 2 meses e cinco dias, quando, foi revogado, não só pela falta de geômetras mas também pelos problemas complexos criados pela forma de demarcação e efetivação dos limites das propriedades rurais.

8.3. Também o regime das sesmarias sofreu uma influência politica perniciosa, onde os simpáticos do sistema obtinham concessões sem sequer saber a localização do imóvel, terminando por criar situações conflitantes com o verdadeiro ocupante, decorrendo em conseqüência, um descrédito ao sistema, acompanhado de instabilizações aflitivas criadas pela insegurança transmitida.

8.4. O sistema sesmarial marginalizou o pequeno e o mé- 
dio lavrador, fortalecendo o latifundiário por excessiva proteção da Corte, fazendo com que os pequenos e médios lavradores fossem dominados em verdadeira sujeição econômica, que no fundo era uma escravidão disfarçada.

8.5. Em decorrência do monopólio dos latifúndios, se arraigou a monocultura, pois só os pequenos lavradores, por suas "roças", praticavam outras culturas, insipientes e improdutivas pelos métodos de plantio sem técnica.

8.6. A política implícita ao regime sesmarial era eminentemente voltada para a ocupação dominial, que ao que parece cumpriu seus objetivos, de vez que o Brasil foi além da linha divisória do Traçado de Tordesilhas e conseguiu repelir as invasões espanholas, francesas e holandesas.

8.7. A transparência da função social da propriedade estava contida implicitamente no regime sesmarial, contudo estava latente, por não ser esta política a primeira a ser executada.

8.8. O retardamento do efetivo exercício da função so- cial da propriedade se deve aos entraves do sistema sesmarial, e pela própria dependência governamental à Coroa, observando-se uma acentuada subserviência administrativa para com o Reino, que não diferenciou o caso particular do Brasil.

8.9. As Sesmarias concedidas sem limitações a uma mesma pessoa, fortaleceu o latifúndio, além do que, propiciou as "entradas" dos pioneiros apenas para acrescerem pela terra, a extensão de seu poder, que não as aproveitavam e não as cediam a quem quisesse para esse fim, sendo raros os casos de constrição para tanto, pela indefinição da noção de aproveitamento.

8.10. O regime sesmarial, contudo, tem o mérito de ser, bem ou mal, o princípio da propriedade rural brasileira, devendo-se computar as notórias deficiências da época, bem como a política diversa do verdadeiro conteúdo das sesmarias, que delas se serviu para outros propósitos de primeira urgência.

\section{ABSTRACT}

In this dissertation I make a detailed study of the Brazilian agrarian issue in light of previous legislation i.e. the Sesmarias (Allotment) Law, as compared with our present agrarian reformation.

The study reveals that the Sesmarias Law (redistribution of land to those who wanted to engage in agriculture) which was passed in Portugal in order to overcome the food shortage that resulted from the abandonment of agriculture in Brazil, was enforced inadequately. This law did not take the peculiarities of Brazil into account. In addition, the law was inappropriately applied when it was eventually used as a guarantee of conquered lands. The grant of Sesmarias was put into practice without adequate criteria since the Monarch used it to favor his political allies. Consequently, frequently allotees were not the people who actually occupied the land. Another problem was in the different interpretations of the measure "league" and was eventually responsible for the emergence of many improductive large landed estates.

The agrarian reformation has not yet been put into practice as it is dependent on an effective agrarian policy which will solve the problem of improductive large landed estates in some regions and which will bring about a satisfactory settlement of the land in others. Such a policy will have to consider the geographical and human peculiarities of each regions so as to best comply with the social nature of properties.

KEY-WORDS: Allotment; Agrarian policy; Agrarian reformation; Large landed estates; Social nature of properties; Political allotment system; Regional peculiarities.

\section{REFERẼNCIAS BIBLIOGRÄFICAS}

1. ALMEIDA, Paulo Guilherme de. A propriedade Imobiliária Rural. LTr, 1980. v. 2.

2. ALVARENGA, Octávio Mello. Manual de Direito Agrário. Forense, 1985 .

3. BALEEIRO, Aliomar. Revista da Fundação Petrônio Portella, 6.

4. BORGES, Paulo Tormin. Institutos Básicos de Direito Agrário. 2 ed. Pró-Livro.

5. DUARTE, Nestor. A Grande Propriedade no Brasil e seus Problemas. In: Reforma Agrária.

6. FERREIRA, Waldemar. História do Direito. Freitas Bastos. v. 1.

7. FLEUIUSS, Max. História Administrativa do Brasil. São Paulo, Cia. Melhoramentos, São Fulo, 1922.

8. GARCIA, Paulo. Terras Devolutas. Belo Horizonte, Oscar Nicolai, 1958.
9. GOMES, Orlando. Revista dos Tribunais, 411:1970.

10. JUNQUEIRA, Messias. As Terras Devolutas na Reformo Agrária. São Paulo, Revista dos Tribunais, 1964.

11. LARANJeIRA, Raymundo. Propedêtica do Direito Agrário. LTr, 1975.

12. LEVI, Augusto, Leituras Escolhidas em Direito Agrário. Fundação Petrônio Portella, MJ.

13. MAIA, Altir de Souza. Revista do Direito Agrário do INCRA, 3.

14. MIGNONE, Carlos Ferdinando. O Módulo Rural. Revista Curso de Direito Agrário, Fundação Petrônio Portella - MJ

15. PORTo, José da Costa. Estudos sobre o Sistema Sesmarial. Recife, Imp. Universitária.

16. PORTO, José da Costa. Revista do Direito Agrário do INCRA, v. 1. 
17. ROCHA, Olavo Acyr de Lima. Revista do Direito Civil, Agrário e Imobiliário, 2.

18. SIMONSEN, Roberto. História Econômica do Brasil. $1^{9} \mathrm{v}$.

19. SODERo, Fernando Pereira. Revista do Direito Civil, Agrário e Imobiliário. 1 .
20. SODERO, Fernando Pereira. O Módulo Rural e seus Implicaçōes Juridicas. LTr.

21. TENORIO, Igor. Curso de Direito Agrário Brasileiro. Saraiva, 1984.

22. ZENUN, Augusto. Direito Agrário e sua Dinâmica. 2 ed. Livraria Universitária de Direito, 1986. 